\title{
AS MULHERES NA POLÍCIA: DAS RELAÇÕES DE PODER NAS TRANSFORMAÇÕES DA HISTÓRIA
}

\author{
Carolina Goulart ${ }^{1}$ \\ Josiane Petry Faria ${ }^{2}$
}

\section{RESUMO}

O artigo objetiva discutir o trabalho policial feminino, apresentando uma breve historiografia de inserção das mulheres na polícia, a partir da perspectiva das relações de poder e da igualdade de gênero. Questiona o poder dominante nas forças policiais e as potencialidades transformadoras da presença da mulher na estrutura da instituição e sua repercussão social. Buscou demonstrar, em um primeiro momento, a construção de uma cultura organizacional heteropatriarcal, a qual narrou a coincidência da história da polícia com a história de homens no poder. Primeiramente, observou-se a exclusão e posteriormente a invisibilidade, depois a discriminação, contudo a maior representatividade feminina trouxe uma desestabilização das relações de poder. A mulher foi deixando o trabalho assistencialista e assumindo o trabalho ostensivo. Assim, por meio do método dedutivo e das técnicas bibliográfica e documental, se pode concluir que muitas dificuldades e obstáculos foram, e ainda são, enfrentados por estas mulheres policiais dentro e fora das instituições as quais pertencem. Todavia, a maior representatividade, associada ao inevitável reconhecimento das mulheres trouxe um desequilíbrio nas forças patriarcalistas institucionalizadas, o qual caminha para a redistribuição de poder com vistas a igualdade de gênero.

Palavras-chave: Cultura organizacional; Igualdade de gênero; Mulheres; Polícia; Relações de poder.

\section{WOMEN IN THE POLICE: FROM POWER RELATIONS IN THE TRANSFORMATIONS OF HISTORY}

\begin{abstract}
:
This article discusses aspects of female police work, presenting the history of women's insertion in the police activity and the conflicts that the presence of these women entailed. At first, an attempt was made to show how history and social factors influenced the practice of a patriarchal "culture" that always placed women as a fragile and incapable being. There were many changes and contributions that women brought to police institutions and, over the years, women's work came closer to ostensible work and away from welfare work. But, without a

1 Mestranda do PPGDireito e docente da Faculdade de Direito da Universidade de Passo Fundo/RS, pesquisadora do Projeto de Pesquisa Dimensões do Poder, gênero e diversidade, Delegada da Polícia Civil do Rio Grande do Sul. Endereço de e-mail:-carolinagoulart@upf.br

${ }^{2}$ Doutora em Direito pela UNISC com Bolsa CAPES PDSE na Universidade de Sevilla/ES, com Pósdoutoramento em Direito pela Universidade Federal do Rio Grande, Professora Permanente do PPGDireito, Coordenadora do Projeto de Extensão Projur Mulher e Diversidade e do Projeto de Pesquisa Dimensões do Poder, gênero e diversidade e Docente Titular da Faculdade de Direito da Universidade de Passo Fundo, jfaria @upf.br.
\end{abstract}

Revista de Gênero, Sexualidade e Direito | e-ISSN: 2525-9849 | Encontro Virtual | v. 7 | n. 2 |

p. $23-41$ | Jul/Dez. 2021. 
doubt, many difficulties and obstacles were, and still are, faced by these police women inside and outside the institutions to which they belong, situations that will be analyzed in the last moment of this research. This study was carried out through several bibliographical consultations and other sources of Law

Keywords: Police work; work and gender, gender equality; organizational culture, Power relations

\section{Introdução}

O trabalho objetiva trazer ao debate acadêmico alguns aspectos sobre o desempenho da atividade policial pelas mulheres, a partir do estudo das relações de poder e da igualdade de gênero. Propõe como questionamento central a verificação do poder dominante nas forças policiais e as potencialidades transformadoras da presença da mulher na estrutura da instituição e sua repercussão social.

Inicia com uma breve historiografia, em contexto mundial, para que se possa visualizar as circunstâncias que levaram à criação de um modelo patriarcal social que até hoje registra a desigualdade nas relações de poder entre os gêneros.

Da contextualização histórica da inserção das mulheres nos órgãos policiais, em perspectiva nacional e internacional passar-se-á, em seguida, a apresentar o percurso dessas mulheres em suas respectivas instituições, destacando as transformações internas e sociais ocasionadas pelo aumento considerável da presença feminina nos órgãos de segurança pública.

Por fim, de forma crítica, analisar-se-á as desconstruções e os avanços que a força do trabalho policial feminino trouxe para os órgãos de segurança, bem como os conflitos internos ocasionados pela inserção, visibilidade e atuação da mulher em um espaço que, até bem pouco tempo atrás, era considerado tradicionalmente masculino. ${ }^{3}$

Finaliza-se a proposta de reflexão, pontuando obstáculos, dificuldades e restrições que enfrentam as mulheres policiais no desempenho de suas funções. Pretende-se, desse modo, de maneira prática e objetiva, refletir sobre as possíveis implicações que a presença feminina traz

\footnotetext{
${ }^{3}$ Exercendo o cargo de Delegada da Polícia Civil gaúcha, testemunho, com frequência, estas transformações e o enfrentamento do preconceito que as policiais mulheres precisam encarar em algumas situações.
} 
para a área da segurança pública, bem como o que representam e quais as expectativas acerca do trabalho policial feminino.

\section{Das mulheres na sociedade heteropatriarcal: uma breve historiografia}

O traçado das características e qualidades masculinas e femininas foram culturalmente construídas, sendo atribuídos a cada um, homens e mulheres, papéis específicos de acordo com o poder dominante, pois sabido é que a biologia não atribui e/ou determinou essas posições e muito menos impôs sua estatização. Mitos culturais se estabeleceram e se perpetuam ao longo do tempo, refletindo em inúmeras desigualdades e discriminações.

O patriarcalismo, como sistema estruturador de relações sociais, está presente na sociedade de forma multifacetada e se expressa de diferentes maneiras em contextos distintos. Para melhor entender as questões sociais relativas às mulheres na sociedade contemporânea, imprescindível a realização de uma análise sobre o sistema patriarcal e as relações de poder exercidas historicamente sobre as mulheres.

O sistema patriarcal pode ser interpretado como uma estrutura que coloca as mulheres em situação de inferioridade em relação aos homens, onde apenas estes detinham o poder e exerciam uma relação de dominação sobre as mulheres, sendo considerado o mais antigo sistema de dominação/exploração entre os povos, sendo seguido pelo racismo. A hierarquia e estrutura do patriarcado contamina toda a sociedade e está impregnada nas relações familiares e sociais e, também, nas relações do trabalho e no Estado, atuando como uma estrutura de dominação que acarreta desigualdades entre homens e mulheres (SAFFIOTI, 2015).

A estrutura característica do patriarcado é colocar a mulher em uma situação de inferioridade, onde o homem exerce domínio sobre a mulher, e o poder se concentra nas mãos destes. As Mulheres não participam de decisões e são excluídas da esfera de poder, que é predominantemente masculino. Assim, a identidade social da mulher foi construída através do papel que a sociedade espera que ela cumpra, determinando-se esta, com precisão, os campos e que pode operar a mulher, da mesma forma como escolhe os terrenos em que pode atuar o homem (SAFFIOTI, 2015)

O patriarcado é a manifestação e institucionalização do domínio masculino sobre as mulheres e a família, e o domínio que se estende à sociedade em geral. Em consequência, as 
mulheres têm acesso limitado ao comando de instituições importantes, concentrando o poder das mesmas nas mãos dos homens. O patriarcado pode, também, ser entendido como a tomada de poder histórica pelos homens sobre as mulheres, cujo agente ocasional foi a ordem biológica, elevada tanto à categoria política, quanto econômica (MENDES, 2017)

Nessa perspectiva, Gago (2020, p. 77) explana que:

[...] Algumas dessas "cenas" não deixam de ressoar em nosso presente, atualizando ao menos três dinâmicas sobre as quais nos estenderemos mais adiante. Por um lado, a relação entre corpos feminizados e dissidentes e terras/territórios comuns, ambos entendidos como superfície de colonização, conquista e domínio. Depois, a criminalização das ações coletivas protagonizadas por mulheres como dinamizadoras de movimentos sociais rebeldes. Finalmente, a autoridade masculina e eclesiástica como chave, mais uma vez, para o chamado à ordem da acumulação capitalista.

A consequência da estrutura do patriarcalismo é um sistema de identificações culturais, no qual a masculinidade é associada a obtenção de renda e dominação sob as mulheres, e a feminilidade é definida em função de serviços sexuais, cuidados do lar e criação dos filhos.

Ocorre que o patriarcado está em crise. Isso é fato. O salário, que servia para os homens como um referente para justificar sua posição dominante na sociedade e funcionava como ferramenta de controle da mulher que deveria permanecer em casa realizando o "trabalho" obrigatório e não remunerado do lar, não está mais assegurado e não serve mais como medida objetiva de autoridade masculina (GAGO, 2020, p. 84).

De acordo com a socióloga (GAGO, 2020, p. 84):

[...] Não é que o patriarcado do salário esteja deixando de exercitar atualmente seu poder de hierarquia e monopólio sobre o manejo do dinheiro. Mas sua crise é maior: o salário, hoje, não está assegurado às maiorias como meio de reprodução. Por esta razão, devido ao colapso do salário como medida objetiva de autoridade masculina, a violência machista se trona "desmedida" no lar: as masculinidades já não estão contidas pelo valor que o salário ratifica e, por isso, necessitam afirmar sua autoridade de outros modos. A crise do desemprego e de precarização e as condições scada vez mais duras de exploração fazem com que a violência doméstica estruture a dominação patriarcal que antes estava mediada e medida pela pelo salário [...].

Somados a este fator, um componente fundamental de mudança é a maior autonomia das mulheres, as quais associam desejo e necessidade na evasão do cenário doméstico para acumular experiências trabalhando também fora de casa, além de uma nova geração de 
mulheres que se atreveram a "desacatar" o patriarcado. Nesse sentido Gago, 2020, p. 84) continua:

[...] A acumulação de desobediências, intensificação das autonomias e a depreciação da figura do homem provedor assalariado desestabilizaram os modos de obediência estruturados na família monogâmica e heteronormativa. As masculinidades desvalorizadas estão em uma busca desesperada e violenta por reestruturação.

Com lugares demarcados na sociedade pela onipresença cultural patriarcal, existem expectativas sociais de comportamento entre homens e mulheres. As mulheres buscam superar dificuldades, rótulos e subordinações que lhes são impostas, procurando se inserir tanto politicamente, como nos mais variados ambientes profissionais. Assim, f cada vez mais notável a ocupação dos mais diferentes espaços pelas mulheres, que, a cada dia, entabulam uma luta constante para reivindicar igualdade em relação aos homens. A atividade policial é um destes espaços e, por isso, passamos agora a analisar a trajetória das mulheres nestas instituições tradicionalmente ocupadas de maneira majoritária pelos homens.

\section{Das mulheres no desempenho da atividade policial no espaço nacional e internacional: o protagonismo das pioneiras}

O trabalho faz parte das atividades que permitem ao ser humano revelar seu valor, manifestando-se através da autoestima e da autoimagem, como no âmbito externo, refletindose no reconhecimento social e servindo como instrumento de pertencimento social. Entretanto, a correlação: trabalho remunerado-produção-poder fez com que as mulheres fossem mantidas à margem da força produtiva e de decisão, lugar este ocupado pelos homens e assim mantido pelo capitalismo dominante.

Períodos de crise, como a Primeira Guerra Mundial, onde mulheres tiveram que assumir postos de trabalhos de maridos e filhos que foram enviados à guerra, ou de transformações importantes relacionadas a força de produção como a Revolução industrial, onde a as industrias passaram a ter interesse pela exploração do trabalho feminino, que marcaram a entrada das mulheres no mercado de trabalho. (SAFFIOTI, 2015)

Apesar da possibilidade do exercício profissional pelas mulheres ter promovido alguma autonomia e independência, não eram tratadas de forma igual com os homens e o 
mercado de trabalho se mostrou como mais um instrumento de exploração. Federici (2011) alega que o que possibilitou o início do capitalismo foi declarar guerra contra as mulheres e suas formas de saber e poder, tendo como denominador comum é desvalorização da vida e do trabalho das mulheres impulsionada pela globalização. A autora mostra que a guerra contra as mulheres é mais antiga do que se imagina e se traduziu na perseguição de bruxas e curandeiras e se reflete até os tempos atuais a todas aquelas catalogadas como heréticas em seus modos de vida.

Já dizia Marx (1988) que o trabalho é fonte produtora de valores que transcende as riquezas materiais, constituindo-se, também, como fonte de relações sociais. Com o passar do tempo e, após muitas lutas travadas pelos movimentos feministas, o trabalho feminino evoluiu e conquistas foram alcançadas, ocupando a mulher espaços inimagináveis, há bem pouco tempo atrás, no mercado de trabalho. Esta transformação no mundo das relações de trabalho, onde as mulheres ganham cada vez mais destaque pelo desempenho de funções que, em visões conservadoras, deveriam ser desempenhadas apenas por homens, é um processo gradativo e progressivo que não admite retrocessos.

As mudanças, que não se restringem apenas a área da segurança pública, mas permeiam todas as esferas laborais, merecem ser analisadas e dimensionadas, especialmente no que concerne a atividades policiais e o impacto da presença de mulheres no efetivo das polícias, tanto do ponto de vista da organização interna das corporações quanto em relação a visão externa, sob a ótica das relações entre a polícia e a população.

Importante observar a história, bem como o contexto social. As mulheres iniciaram sua trajetória nas polícias do Brasil e no restante do mundo para que as conquistas e dificuldades da atualidade sejam melhor compreendidas. Assim, nos próximos parágrafos, passar-se-á a analisar alguns fatos marcantes da história relacionados ao desempenho de atividades policiais por mulheres.

Os primeiros registros de mulheres atuando em funções policiais datam entre os anos de 1893 e 1910, conforme destaca Major Najara Santos Silva, historiadora e chefe do museu da Brigada Militar, em artigo escrito para a Revista da Brigada Militar em edição especial para o seminário internacional mulheres e segurança pública. Referidos registros ocorreram nos Estados Unidos, sobressaindo-se a atuação de Mary Owens, mulher que trabalhava em casos 
que envolviam crianças e outras mulheres, senda ela a pioneira em receber a possibilidade de poder de prisão naquele país no ano 1893 ( SILVA, 2012, p.4). ${ }^{4}$

A major ainda relata que em 1895, no mesmo país, Lola Baldwin, também recebe o mesmo poder de prisão e comando de um grupo de outras mulheres que desempenham a função de assistência social. Mas foi só em 1910 onde, pela primeira vez, uma mulher foi contratada por um departamento policial para exercer plenos poderes de polícia. $\mathrm{O}$ fato acorreu em Los Angeles, Califórnia, e a pioneira chama-se Alice Stebbin Wells. (SILVA, 2012 p.4)

Na Europa, o país pioneiro foi a Inglaterra, que no ano de 1915 formou o Women Police Volunteers (WPS), um grupo de mulheres voluntárias que formavam uma espécie de força policial feminina que patrulhava parques e cinemas para evitar atos de imoralidade. Já na França, as primeiras mulheres policias entraram para a polícia no ano de 1934 e desenvolviam atividades vinculadas a crianças vulneráveis e patrulhamento das ruas e, apenas em 1982, igualaram-se aos homens no desempenho da função policial. (SILVA, 2012, p.4)

A introdução da Polícia Feminina no Brasil se espelhou na satisfatória experiência europeia e americana, que destacou o desempenho feminino na solução de questões relacionadas a ocorrências envolvendo mulheres e menores, de polícia preventiva e assistencial. O estado pioneiro na inserção de mulheres na polícia foi São Paulo que, em 12 de amio de 1955, criou o Corpo de Policiamento Especial Feminino, vinculado a Polícia Militar, que contava com 12 mulheres que patrulhavam em duplas rodoviárias e aeroportos. Este fato serviu de modelo para outras polícias criarem contingentes femininos, mas foi, efetivamente, apenas no início dos anos 80 que a atividade policial, até então era considerada essencialmente masculina, sofreu significativas mudanças em nosso país. Passávamos por um período de transição política pós-ditadura, de luta pela democracia, onde a imagem das instituições policiais era de truculência e repressão. Com objetivo de mudança desta visão desgastada dos agentes de segurança, foram admitidas as primeiras mulheres em trabalho policial. Elas representavam valores de inteligência e capacidade dissociados da força física, trazendo uma nova concepção para a segurança pública. (SILVA, 2012)

\footnotetext{
${ }^{4}$ Importante registrar os nomes das mulheres, eis que silenciadas, menosprezadas e invisibilizadas pela história patriarcal.
} 
No Rio Grande do Sul, as primeiras mulheres ingressaram nos quadros da Polícia Civil na década de 70, quando 41 mulheres prestaram concursos para o cargo de investigador de polícia, sendo esta força de segurança do nosso estado uma das pioneiras a abrir espaço para as mulheres no Brasil. Em relação a Brigada Militar, foi em 1985 o ingresso das primeiras policiais que integraram a Companhia de Polícia Militar Feminina, que contava com um efetivo de 135 policiais, onde, na ocasião de suas formatura na Academia de Polícia Militar, homenagearam Anita Garibaldi, mulher símbolo de coragem e luta. O processo de reestruturação d Polícia Militar gaúcha foi marcado pela integração da referida companhia ao efetivo normal no ano de 1997, com unificação dos quadros, onde homens e mulheres passaram a desempenhar a mesmas funções e conquistaram igualdade de condições. (SILVA, 2012) p.4)

Assim, pode-se constatar que a participação feminina nas polícias vêm aumentando progressivamente nos últimos anos, sendo importante analisar o impacto da presença e da representação da mulher nas corporações. Importante destacar o conflito entre a crescente representatividade feminina e manutenção da reprodução de estereótipos de gênero, bem como a influência na carreira da mulher policial.

\section{Das transformações sociais e organizacionais produzidas pelas mulheres no desempenho da atividade policial: Do abalo nas estruturas de poder}

A predominância masculina no desempenho do trabalho policial reproduz padrões de gênero presentes na sociedade, alimentados pela cultura patriarcal que dogmatiza a posição de inferioridade da mulher. Estes estereótipos e posicionamentos são reproduzidos nas estruturas das organizações policias brasileiras como um todo, e, quiçá, em todas as forças de segurança.

Diante de tal problemática é importante trazer o poder da cultura organizacional. MINTZBERG (2000) afirma que ela é a base da organização, refletindo crenças comuns que produzem costumes e rituais de comportamentos. Conforme o autor, esta força cultural, em um ambiente laboral, legitima valores e hábitos dos membros de uma organização.

A cultura organizacional é compreendida por Fleury (1996, p. 22) como: 
[...] um conjunto de valores e pressupostos básicos expressos em elementos simbólicos, os quais, em sua capacidade de ordenar, atribuir significações, construir a identidade organizacional, tanto agem como elementos de comunicação e consenso, como ocultam e instrumentalizam as relações de dominação [...]

A Cultura organizacional consiste, então, num conjunto complexo de crenças e valores que definem uma organização. Para Schein (2009, p. 16) constitui em um padrão impositivo de suposições básicas compartilhadas, o qual foi aprendido por um grupo à medida que solucionava seus problemas de adaptação externa e de integração interna. Esse padrão normativo/regulatório tem funcionado de maneira satisfatória ao ponto de ser considerado válido, por conseguinte, ensinado aos novos membros como o modo natural/normal de perceber, pensar e sentir.

Assim, é como se a cultura organizacional guiasse comportamentos dentro das instituições e estabelece padrões difíceis de desmistificar. Bertero (1996, p. 35) explica que:

[...] a cultura organizacional é criada, inserida e manipulada ao mesmo tempo em que faz restringir atos e comportamentos. E sempre é, uma luta por padronização e integração. Além da cultura, que é imposta aos novos membros de uma determinada instituição, o poder nas organizações é elemento dotado de energia, razão pela qual, possui o atributo de moldar e transformar organizações. Para tanto, quando se fala em cultura organizacional, não se pode olvidar de apresentar o poder enquanto elemento modelador [...]

Considerando o processo de naturalização causado pela reprodução permanente da cultura organizacional associado aos conceitos de disciplina e operacionalidade, observa-se a existência quase impercebível desse conjunto de hábitos e crenças próprios das instituições. Nesse cultura, onde as mulheres são invisibilizadas a partir de mitos de fragilidade, insegurança e inferioridade, importante avançar para destacar as lutas no enfrentamento às desigualdades de gênero e para a derrubada dos paradigmas patriarcalistas.

Muitas são as lutas feministas contra a arcaica, porém ainda dominante cultura patriarcal, revelando o pensamento retrógrado que, ainda nos dias de hoje, influencia na desigualdade entre homens e mulheres, estimulando uma ideologia de gênero onde à mulher caberia determinados "papéis", tais como, por exemplo, cuidar da cassa e dos filhos enquanto aos homens o sustento financeiro da família. Essas ideias representam expectativas sociais criadas por conservadores, para a manutenção da supremacia do poder heteropatriarcal, baseadas em costumes e práticas organizadamente propostos para o fim de manter a ordem e os privilégios da desigualdade. 
Nesse ponto, relevante dizer que existe uma aliança recente entre neoliberalismo e conservadorismo, contra quem os movimentos feministas precisam lutar, que defende uma ideologia de gênero que "empobrece massivamente e que propõe que o antineoliberalismo consiste em retornar a família como confinamento, ao trabalho com patrão e a maternidade obrigatória" (GAGO, 2020, p. 17).

Apesar de muitas conquistas nas lutas dos movimentos feministas, Boaventura (2020) destaca que "Finalmente, o patriarcado induz a ideia de estar moribundo ou enfraquecido em virtude das vitórias significativas dos movimentos feministas nas últimas décadas, mas, de facto, a violência doméstica, a discriminação sexista e o feminicídio não cessam de aumentar."

Tratar a mulher como um ser inferior é um produto histórico da sociedade conservadora que maximiza as desigualdades. Wilsem (2018) esclarece que pesquisa a inserção das mulheres no exército brasileiro, que atribuir papeis socias a homes e mulheres só acentua as diferenças:

[...]Por conseguinte, mister ressaltar que, os gêneros são uma categoria cultural, enquanto o sexo é uma categoria biológica. Assim, as qualidades masculinas e femininas são culturalmente construídas e a sociedade atribui a eles papeis específicos, o que causa inúmeras desigualdades, inferioridades e discriminações.

Ainda sobre uma possível construção social de inferioridade feminina, em contrapartida de uma valorização masculina, Wilsem (2018) continua sua análise tecendo que o patriarcalismo, como sistema estruturador de relações sociais, está na sociedade de forma dissimulada e multifacetada se expressando de diferentes maneiras e em contextos distintos. A denúncia desse pressuposto é fundamental para compreender as questões relativas às mulheres na sociedade contemporânea e desnaturalizar a desigualdade.

Nesse contexto a importância dos movimentos feministas se torna inquestionável, eis que questionaram o fundamento cultural da dominação, nas conquistas dos direitos das mulheres. Referidos movimentos ultrapassaram seus objetivos originários, que visavam fazer desaparecer as discriminações das quais as mulheres eram vítimas, fazendo com que elas alcançassem a igualdade de chances. Novos modelos culturais foram criados onde não se admitem qualquer tipo de hierarquia entre gêneros, ou por razões deste (TOURAINE, 2010) 
Historicamente a mulher sempre foi excluída da esfera de poder e decisão, inclusive dentro da própria família. Ao analisar-se a questão da mulher como integrante das forças policiais, se percebe na prática que houve um direcionamento do policiamento feminino para os cuidados com a população, mais uma atuação preventiva do que o combate ostensivo a delitos. Percebe-se, também, poucas mulheres em cargos de chefia, principalmente em departamentos operacionais e de repressão ao crime organizado, por exemplo.

A participação dos homens é diferente das mulheres nos órgãos de segurança pública, não só do ponto de vista quantitativo, já que eles representam um número muito maior de policiais, como também em relação a sua participação na estrutura das instituições e na ocupação de determinados cargos. Sem dúvida ocorre a marginalização das mulheres em certos postos de trabalho e em centros de poder, fato que não pode ser tratado com naturalidade já que imposto pela arcaica tradição cultural patriarcal. (SAFFIOTI, 2015)

As mulheres têm razões de sobra para se opor ao machismo reinante em todas as instituições sociais, já que o patriarcado não se restringe apenas ao âmbito familiar, mas atravessa a sociedade como um todo. A cruel discriminação sofrida ao longo do tempo pelas mulheres, resultantes desta dominação histórica pelo homem, excluídas de participação social e poder familiar, resultou reações como as lutas das mulheres pela ocupação de espaços sociais, políticos e econômicos que historicamente lhe foram negadas. (SAFFIOTI, 2015).

No que se refere a organização das Polícias Militares, Capelle (2010, p.17) afirma que a entrada das mulheres chega para transformar a visão que a sociedade tem da instituição, que é vista como agressivo braço do Estado com finalidade repressora da criminalidade. Em contrapartida, referidas autoras destacam o ambiente culturalmente segregador da instituição:

[...]A Polícia Militar, analisada como um espaço organizacional de interação social, pode ser considerada uma espécie de gueto masculino no qual se admitiu o ingresso de mulheres há pouco tempo. A inserção de mulheres na organização, principalmente as do oficialato, tem ocorrido, predominantemente, em funções administrativas e de relações públicas - tidas como atividades-meio e não atividades-fim da Polícia -, percebendo-se maior dificuldade de inserção daquelas policiais que optam por seguir carreira no policiamento operacional. Somado a isso, tem-se um contexto em que a questão da violência urbana vem pressionando os órgãos de segurança pública por melhores resultados. E percebe-se também uma ação da Polícia Militar no sentido de mudar sua percepção por parte do público, passando de uma organização com a imagem marcada pela agressividade e repressão para outra que se coloca a serviço da comunidade, com um caráter mais preventivo e educativo. 
A diversidade de perfis humanos nas instituições de segurança pública, altera comportamentos e desafia as organizações a crescerem e se desenvolverem para um trabalho policial mais humano e menos robotizado, trazendo uma nova concepção de atividade policial.

Importante o debate sobre o poder da cultura organizacional sobre a cultura policial, marcada por disparidades nas relações de poder entre os gêneros. A igualdade de oportunidades e índices de representatividade feminina cada vez mais crescentes são o sinal de que estereótipos devem ser abandonados. Porém, desigualdades não podem se apenas disfarçadas, a mudança deve ser real e concreta e, para que isso ocorra, necessário que ocorra a quebra das barreiras sociais e institucionais, com objetivo do equilíbrio e igualdade de gênero, também dentro dos órgãos policiais.

\section{Do desequilíbrio das relações de poder na cultura organizacional das polícias: As dificuldades e restrições enfrentadas pelas mulheres policiais no exercício profissional decorrentes da desigualdade de gênero}

O cotidiano da mulher por si só apresenta particularidades diferenciadas. Além de questões hormonais que influenciam diretamente na qualidade de vida e humor, uma rotina com somatório de responsabilidades domésticas e laborais, jamais remuneradas, já seria suficiente para serem classificadas por muitos como dificuldades. Porém, não é a postura que se percebe na maioria das mulheres, que se negam a vitimização e lutam para desconstrução de percepções sexistas, onde qualidades que as diferenciam dos homens, como sensibilidade, organização e capacidade de superar pressão e adversidades são destacadas como demérito ou elemento à justificar a exploração.

No desempenho de funções policiais não podia ser diferente: são significativas as dificuldades enfrentadas pelas mulheres! Condutas discriminatórias que ainda persistem no âmbito interno das forças de segurança no Brasil e na sociedade como um todo, e tornam desafiador o exercício do trabalho policial para uma gama de mulheres que escolheram servir a comunidade através do desempenho da função policial. Em muitas corporações ainda existem resistências internas quando mulheres são incumbidas a desempenhar alguns papeis, 
tipicamente exercidos por homens, existindo forte tendência de aproveitamento das policiais mulheres em áreas administrativas.

Percebe-se que na prática, são inúmeras as barreiras e dificuldades enfrentadas pelas mulheres no desempenho de suas funções dentro de instituições policiais. A atividade de policiamento e investigação, historicamente desempenhadas por homens, tem despertado o interesse das mulheres, que cada vez mais vem prestando concurso público para os cargos de carreiras policiais, sendo aprovadas em número igual ou superior aos homens nos referidos certames.

Alguns homens, representando uma parcela significativa do ambiente policial, acreditam que razão e objetividade seriam características exclusivamente masculinas, classificando as mulheres como seres mais frágeis que merecem proteção e que, por desenvolverem certas habilidades emocionais, não teriam a mesma aptidão para o serviço policial que, na visão destes, exigiria força bruta e postura autoritária.

Já em relação a posições de chefia e comando, tipicamente incumbidas a homens, quando exercidas por mulheres dentro das instituições policiais, as dificuldades se relacionam a questões de submissão dos subordinados homens, que muitas vezes, boicotam a liderança feminina e têm comportamentos antiprodutivos. Infelizmente, ainda reina o estereótipo de que mulheres não tem competência para assumir trabalhos de maior responsabilidade, alimentando com este tipo de comportamento o status de inferioridade da mulher sustentado pela cultura patriarcal.

Em contrapartida, percebe-se que existe movimentos no sentido de mudar a imagens de organizações policiais, antes marcadas pela agressividade e repressão, dando destaque a serviços comunitários com caráter educativo e preventivo. Policiais mulheres tendem a se encaixar melhor neste tipo de função, acreditam, ainda, uma parte de policiais masculinos preconceituosos, que tendem a rejeitar este tipo de trabalho que é constantemente "diminuído" na visão "masculinizada" das polícias.

Infelizmente ainda impera em uma parcela da sociedade a visão de que as mulheres tem menos desenvolvidas características como razão, equilíbrio e força, faltando-lhes objetividade e sobrando-lhes sensibilidade. Esta condição feminina, na visão destes poucos, somada a grande dificuldade de conciliar inúmeras responsabilidades como administração do 
lar e filhos com a atividade profissional, dificuldade de mobilidade geográfica e separação da família, dificulta o desempenho da atividade policial pela mulher e limita, consequentemente, o acesso das mesmas a posições de comando e chefia.

Assim, para aqueles que acreditam que existe um "modo feminino" de trabalhar e administrar, onde as mulheres teriam habilidades "naturais" próprias e particularidades da vida pessoal inconciliáveis com a dedicação que a carreira policial exige, se faz necessário uma divisão sexual do trabalho dentro das corporações policiais, com forte tendência de que as mulheres desempenhem funções menos operacionais e fora da linha de frente de combate à criminalidade.

Assim, podemos perceber que os papeis definidos dentro dos órgãos policiais reproduzem, muitas vezes, os instituídos socialmente, marcados pela dominação masculina. Por isso, tantas mulheres policiais estão em serviços administrativos e cartorários, com a desculpa de que, por serem mais frágeis e destituídas de força física, merecem serviços proteção e menos perigosos.

Os homens, frequentemente, acreditam estar em condições superiores a mulher no que se relaciona a atividade profissional, já que não têm de lidar com instabilidades hormonais, administração do lar e organização da rotina dos filhos. E talvez, de fato, realmente estejam mais aptos a desempenhar com melhor concentração suas funções, já que a mente está "limpa" de maiores responsabilidades e teriam mais facilidade de manterem-se focados.

Assim, ao invés de destacarmos o valoroso trabalho de profissionais mulheres que, com maestria, conciliam inúmeras atividades e responsabilidades, as mesmas são discriminadas no mercado de trabalho, com menos chances de ascensão profissional e acessos a cargos de comando e chefia, já que existe a crença de que elas têm menos tempo para dedicar-se a atividade laborativa.

Precisamos destacar que a questão da maternidade influencia diretamente na visão social do trabalho feminino. Conforme preceitua GIFFIN (1993), a legislação trabalhista que traz a mãe direitos, como o afastamento do trabalho pela licença-maternidade e o direito à amamentação, dificulta sua competição com os homens, de acordo com a lógica masculina de gestão que ainda predomina nas organizações. 
No Rio grande do Sul, esta não é a realidade atual, onde, pela primeira vez na história da Polícia Civil gaúcha uma mulher encontra-se no comando da instituição. A Delegada Nadine Tagliari Farias Anflor, que_atua na profissão há mais de 15 anos, desde 2018 assumiu o principal posto da Polícia Civil.

A Chefe da Polícia Civil riograndense atribui a conquista e a crescente amplitude do espaço das mulheres dentro da Polícia Civil do Rio Grande do Sul ao trabalho desempenhado pelas primeiras mulheres policiais na década de 1970. Foi em agosto deste ano, o marco em que ocorreu a participação de mulheres em turmas de formação para o cargo de investigador de polícia na Academia da Polícia Civil (ACADEPOL) gaúcha, sendo esta uma das primeiras forças de segurança do Brasil a admitir mulheres que, apesar de representarem apenas $5 \%$ da turma na época, o fato já foi considerado um grande avanço para a história da Polícia Civil e, quiçá, para todas as polícias brasileiras. Estas mulheres abririam caminhos, romperam obstáculos e padrões de época.

Já no âmbito da Brigada Militar, Calazans (2004) destaca que a referida instituição entrou no processo de feminização sem promover um processo de construção, ou discussão, apenas aderindo à tendência no mundo do trabalho. A autora acredita que ainda que as mulheres sejam identificadas com um novo modelo de polícia, a instituição não estava preparada para recebê-las e não se organizou com estratégias de adaptação relacionadas a sua inserção no ambiente policial. (LIMA, 2002; CALAZANS, 2004)

Não há dúvida que a presença das policiais femininas causou (causa) um certo desconforto aos homens policiais, que tentam, algumas vezes, estabelecer uma espécie de "hierarquia" sob pretexto de orientação, colocando o trabalho da policial mulher sob constante supervisão de colegas do gênero masculino, e com uma tendência de encaminhamento de casos considerados de baixa periculosidade, agarrando-se a concepção de que o combate à criminalidade, que é a tarefa principal dos órgãos de segurança como um todo, é naturalmente masculina.

Certamente, a atividade policial está associada ao risco e exposição a perigos, com rotina de treinamentos intensivos que exigem disciplina e obediência hierárquica, princípios básicos de qualquer instituição de segurança pública. Porém, a maior dificuldade enfrentada pelas mulheres policiais não são duras provas físicas ou psicológicas as quais precisam ser 
submetidas quando da realização do concursos públicos para as carreiras policiais, ou a disciplina férrea e perigos enfrentados na realidade da função policial, mas sim a resistência masculina social e falta de valorização de seu trabalho.

Um novo paradigma para órgãos de segurança pública nasce a partir da inserção das mulheres na função policial, e elas não se cansam de mostrar sua competência no desempenho da mesma, abrindo-se, cada vez mais, às mulheres a possibilidade de demonstração de sua capacidade de produção e liderança. Certamente barreiras vêm sendo quebradas e as restrições vem caindo com o passar do tempo, mas a questão ainda merece ser objeto de intenso debate.

Assim, ao abrirem-se possibilidades para que mulheres passassem a desempenhar funções que eram, até bem pouco tempo atrás, essencialmente masculinas, um objetivo foi, certamente, atingido: a transformação da visão que a sociedade pós ditatura tinha das polícias. As mulheres ocuparam espaços nas instituições de segurança públicas brasileiras transformando as polícias em órgãos mais humanizados e sensibilizados com os problemas sociais.

Porém, muito ainda deve se buscar no que se refere ao reconhecimento e a igualdade de oportunidades das mulheres quando no exercício da atividade policial. Uma nova concepção de segurança pública, que conta com a sensibilidade e dedicação da mulher para atingir resultados de excelência, com objetivos que vão além da repressão e buscam também a prevenção de crimes, aliados a força física e objetividade masculinas, devem ser pensada. Não se pode mais compactuar com estereótipos de gênero frente ao trabalho policial, tampouco a sexismos socias que atribuem a mulher um papel de submissão, inferioridade e incapacidade.

\section{Considerações Finais}

O artigo em questão representa apenas parte de uma investigação científica voltada a descontruir outro mito, de que mulher policial não pode, não é e não deve ser pesquisadora. Dentre as metas desta pesquisa está a missão de romper esse estereótipo e facilitar, por meio da apresentação de resultados científicos, a destruição dos mitos construídos e permanentemente reforçados pela cultura organizacional policial, os quais desfavorecem as mulheres. 
Em num primeiro momento, foi importante destacar alguns pontos sobre o sistema patriarcalista, relendo a histpriografia da mulher na sociedade e, posteriormente, nas instituições de segurança pública. Destacou-se, como razão de verdade e justiça nomes de mulheres silenciados pela desigualdade operante na cultura organizacional, também marcadamente heteropatriarcal, sendo que as lutas dos movimentos feministas, não podiam ser esquecidas, sob pena de ceder à esse poder dominante e excludente.

Numa terceira etapa, foi importante registrar as transformações que o trabalho policial feminino provocou nas instituições de segurança, destacando-se os obstáculos enfrentados pelas mulheres no desempenho da função policial, na dificuldade de conciliação do trabalho com as atividades domésticas e a família, elemento que comprova a predominante desigualdade de gênero. bem como no preconceito que ainda existe quando do desempenho da atividade policial pelo gênero feminino.

A partir da investigação, conclui-se que é possível superar as desigualdades entre gêneros e garantir avanços na perspectiva da igualdade de gênero com o aumento quantitativo de mulheres exercendo cargos públicos dentro das instituições de segurança pública brasileiras, constatando-se que para que as mulheres e os homens alcancem o pleno desenvolvimento de seu potencial humano, eliminadas devem ser, do ponto de vista hierárquico, as divisões sexuais do trabalho, devendo a condição de ser homem ou mulher não ser considerada para denotar desigualdades.

O caminho para a superação dos obstáculos mantidos pela cultura organizacional patriarcalista ainda é longo. Deveras, as mulheres buscam, em suas reivindicações, não só igualdade, mas também liberdade e dignidade, rejeitando todos os tipos de dependência e influências patriarcais que definem e impõem a maneira de viver, pensar e agir da mulher. Assim, justificada a necessidade de rever as relações de poder e de promover a desconstrução dos mitos sociais e organizacionais com o fito de alcançar a visibilidade, o reconhecimento e a equidade de gênero nos órgãos de segurança pública, pois só teme a igualdade quem está em posição de privilégio. 


\section{REFERÊNCIAS}

BERTERO, Carlos Osmar. Cultura organizacional e instrumentalização do poder. In: FLEURY, Maria Tereza Leme; FISCHER, Rosa Maria (Org.). Cultura e poder nas organizações. 2. ed. São Paulo: Atlas, 1996.

SANTOS, Boaventura de Souza. A cruel pedagogia do vírus, Coimbra: Almedina, 2020.

CALAZANS, Marcia Esteves. Mulheres no policiamento ostensivo e a perspectiva de uma segurança cidadã. São Paulo: São Paulo em Perspectiva, 2004.

CAPPELE, Monica Carvalho Alves; MELO, Marlene Catarina de Oliveira Lopes. Mulheres Policiais, relações de Poder e de Gênero na Polícia Militar de Minas Gerais. RAM. Revista de Administração Mackenzie, v. 11, p. 1-25, 2010.

GAGO, Verônica. A potência feminista ou o desejo de transformar tudo. São Paulo: Elefante, 2020 .

GIFFIN, Karen Mary. Transição de gênero: a condição feminina na sociedade atual. In: CONFERÊNCIA DA ORGANIZAÇÃO PAN-AMERICANA DE SAÚDE, 1993, Rio de Janeiro. Rio de Janeiro: Organização Mundial de Saúde, 1993

FLEURY, Maria Tereza Leme. O desvendar a cultura de uma organização- uma discussão metodológica. In: FLEURY, Maria Tereza Leme; FISCHER, Rosa Maria (Org.). Cultura e Poder nas organizações. 2. ed. São Paulo: Atlas, 1996.

FREDERICI, Silvia. Calibán y la bruja: Mujeres, cuerpo e acumulación originaria. Buenos Aires: Tinta Limón, 2011. Ed brasileira: Calibã e a bruxa: Mulheres, corpo e acumulação primitiva. Trad. Coletivo Sycoraz. São Paulo: Elefante, 2017.

MARX, Karl. O Capital. Rio de Janeiro: Bertrand Brasil Editora, 1988.

MENDES, Sorais da Rosa. Criminologia feminista: novos paradigmas. 2. ed. São Paulo: Saraiva, 2017

MINTZBERG, Henry et al. Sáfari de estratégia: um roteiro pela selva do planejamento estratégico. 2 ed. Porto Alegre; Boockmam, 2000.

SAFFIOTI, Heleieth Iara Bongiovani. Gênero, patriarcado, violência. 2 ed. São Paulo: Expressão Popular: Fundação Perseu Abramo, 2015.

SCHEIN, Edgar H. Cultura organizacional e liderança. Tradução de Ailton Bomfim Brandão. São Paulo: Atlas, 2009.

SILVA, Najara Santos. Mulheres nas policias militares. In REVISTA DA BRIGADA MILITAR - ano II - No 2- março de 2012- publicação especial para o seminário internacional mulheres e segurança pública. Disponível em: https://www.brigadamilitar.rs.gov.br/upload/arquivos/202009/28130800-mulheres-na-bm.pdf.

Acesso em: 11 de agosto 2021 
TOURAINE, Alain. O Mundo das mulheres. Tradução de Franciso Morás. 2. ed. Petrópolis: Vozes, 2010.

WILMSEN, Janiquiele. Relações de gênero e poder simbólico: O princípio da igualdade e a inserção das mulheres no exército brasileiro. Dissertação de mestrado Universidade de Passo Fundo. 2018. 